\title{
Towards the Science of Managing for Innovation: Interim Discussions on Innovation Research Methodologies
}

\author{
Anne-Laure Mention \\ anne-laure.mention@rmit.edu.au | RMIT University, Australia \\ João José Pinto Ferreira \\ jjpf@fe.up.pt | INESC Technology and Science, Faculty of Engineering, University of Porto, Portugal \\ Marko Torkkeli \\ marko.torkkeli@lut.fi | Lappeenranta University of Technology, Finland
}

In our previous editorial, we positioned our perspective and introduced the acronym "ROTRUS" to characterise the science of managing for innovation as - Real world, Observable, Testable, Replicable, Uncertain and Social. Specifically, we argued that methods that draw on point-in-time beliefs, perceptions and de-humanised data in a complex and evolving social setting of innovation management pose a challenge for replicability. We warned innovation researchers to avoid the pitfalls that might foster pseudoscience and generalised assumptions from information that is still in the proto-science stage. Drawing on longstanding understanding in psychology of the whole human, we discussed the need to explore methods that capture brain, mind and behaviour aspects in innovation management, spanning the analysis from individual to group and societal levels. In this editorial, we move the discussions forward by focusing on one plausible methodological approach to advance the science of managing for innovation - behavioural experiments. In the following sections, we explain our methodological stance or in other words our world view followed by a brief review of behavioural experiments and their relevance to innovation research. We conclude with a foreword on our final editorial in the series titled the science of managing for innovation.

\section{Methodological stance}

If we are to believe that actions are a result of implicit judgement of value and actions accentuate problems (Malachowski 2013), then there remains no validity in the distinction of theoretical and practical perspectives. Truth cannot be found merely through questions in theory, and any such 
separations of questions of truth are only questions for the defensible means of action (Newman and Benz 1998). Important to note that scholars have for decades reasoned for the 'plurality of paradigms' to progress the science of management, and in doing so, have called on researchers to embrace the 'fuzzy boundaries' (Cannella and Paetzold 1994, 332). We agree with these and other innovation researchers (see Adams et al. 2016; Ferraro, Etzion and Gehman 2015) and believe that individuals adopt a pragmatic perspective when managing for innovation. Resembling a realtime dynamic game with its many players, individuals in innovation management may experience situations and happenstance that does not follow strict sequence of events, rather decisions may emphasize reliance on patterns of interactions as the game unfolds (O'Donohue 2016).

Although largely understood in a broader management context, research at the intersection of innovation and knowledge management is yet to embrace a holistic and pragmatic agenda (O'Donohue 2016). Perhaps, there is a need for cross-disciplinary search when advancing the science of managing for innovation. For instance, Antons and Pillar (2015) argued that individual behavioural outcomes in open innovation are closely associated with displaced cognition, yet management scholars have long known that it is not the conflicting cognition rather it is how one resolves the cognitive discrepancy that guides behavioural responses (Hinojosa, Gardner, Walker, Cogliser, and Gullifor 2017). Based on these purviews, it might be tempting to assume that one's adaptive cognition is merely a representation of perceived behavior. Yet, Ajzen (2011) does not believe so, since application of his theory of planned behaviour has repeatedly proved that cognition is merely a formative indicator and it is ultimately one's intention that predicts behaviour (Ajzen, 2011; cf. Sniehotta, Presseau, and Araújo-Soares 2014; Kautonen, Gelderen, and Fink 2015). Indeed, Covey (1989) drew attention to the patterns of mental representations affecting cognition and attention to experiences, both from individualistic and collective perspective that shapes the humanistic purview of the world and the sense of humanly 'being'. Thus, we argue that actions enacted by individuals during the innovation process are nothing more than mental lessons which cannot be proved or disproved until acted upon and empirically observed with some objectivity. In this view, the mental representations that reflect hypothetical internal cognitive symbols of an external reality may be logically recognised through real world observations, but the final test of its accuracy requires objective evidence through hypotheses testing (Maddux and Donnett 2015). This calls for discounting of a priori dominant position to positivism or interpretivism paradigms, in turn requiring a pragmatic epistemology to find the best possible alternative and encourage diverse intellectual purviews through multi-disciplinary choice that powers the scientific and practice-oriented dialogue in the discourse.

\section{Behavioural experiments as a plausible method}

Weimann (2015) identified five research settings (Fig 1) - (1) neoclassical based on game theoretical models with highest probability of establishing causality, (2) traditional research capturing self-reported data collected using surveys or patent statistics with inherent endogeneity and selectivity issues, yet high-level of external validity and feasible application, (3) natural experiments embedded in the 'field' allowing for substantiation of causality within contextual parameters, but lacking applicability across contexts and domains, (4) randomised field experiment in which treatment conditions are recognised in real-life incidents, offering the 'gold standard' of expe- 
rimentation with an optimal trade-off between causal inferences and external validity, and (5) laboratory experiments which provide the high-level causality and applicability, offering a pragmatic solution to expensive randomised field experiments and novel insights to phenomenon inaccessible by field innovation experiments. Weismann (2015) argued that each type of research setting has it strengths and limitations and ultimately, the selection should be guided by (1) research objective, (2) availability of data and (3) possibility of collecting data in through field experiments. Here, we briefly discuss the relevance of behavioural experiments, a pragmatic methodological solution between the positivism and interpretivism dichotomy.

Behavioural experiments are generally defined as a research methodology for controlled data generating from individual decision-makers who face real consequences to their responses, under random assignment, active participation and manipulation of context (real-world, role-playing). They have been widely applied in literature. The appendix to this editorial provides a short-list of studies which highlight how scholars across various disciplines have embraced behavioural experiments to unveil the idiosyncrasies at various decision-points within contextual boundaries. Be the subject of social co-creation, entpreneurial opportunity evaluation, exploration-exploitation or cheating and dishonesty, behavioural experiments have provided valuable insights into otherwise complex psychological processes. The approach provides a feasible solution to examine the cause and effect, a method that has also become a vital component of innovation research in recent years (Brüggemann and Bizer 2016; Chetty 2015; Sørensen, Mattsson and Sundbo 2010). Behavioural experiments draw on conventional experiments, yet embrace context dependencies, to test the effects on a dependent variable by manipulating the independent variables and controlling for all other conditions (Brüggemann and Bizer 2016; Gross and Krohn 2005). Individuals are randomly assigned to either only one treatment (between-subject design) or are exposed to multiple treatments (within-subject design) (see table 2, for a review see Charness, Gneezy, and Kuhn 2012). The manipulation process is typically implemented by assigning participating individuals randomly to groups that are treated differently, allowing for deeper understanding of the cognitive and social preferences to interactions and exchanges at isolated innovation decisionpoints (Willer and Harry 2007). This rationale supports the logic that in the pragmatic setting of innovation management where interactions are complex, disorderly and iterative (Fischer 2001), behavioural experiments provide a complementary and often alternative view to the roles of actors, the interrelatedness of variables and the interdependency of activities (Chetty 2015; Madrian 2014).

It is important to note that although experiments are mostly associated with quantitative methods, behavioural experiments may equally employ qualitative methods. Indeed, it may not be prudent to believe that experimental findings from a controlled laboratory setting would reveal effects same as those found in natural settings (Shaughnessy, Zechmeister and Zechmeister 2015). For instance, qualitative methods may become useful when contextual complexities pertaining to the variables under investigation cannot be conceptualized quantitatively or where it is not possible to undertake statistical methods. Action Research and Action Learning aimed at altering the practice through intervention and manipulation of causes are typical examples of such experiments (Baskerville and Wood-Harper 1996). Besides, a commonly implemented technique in studies involving human behavior have relied on conversational analysis (CA). Although criticized for redefining the basic constructs of mind and behaviour (Button, 1991; Kitzinger, 


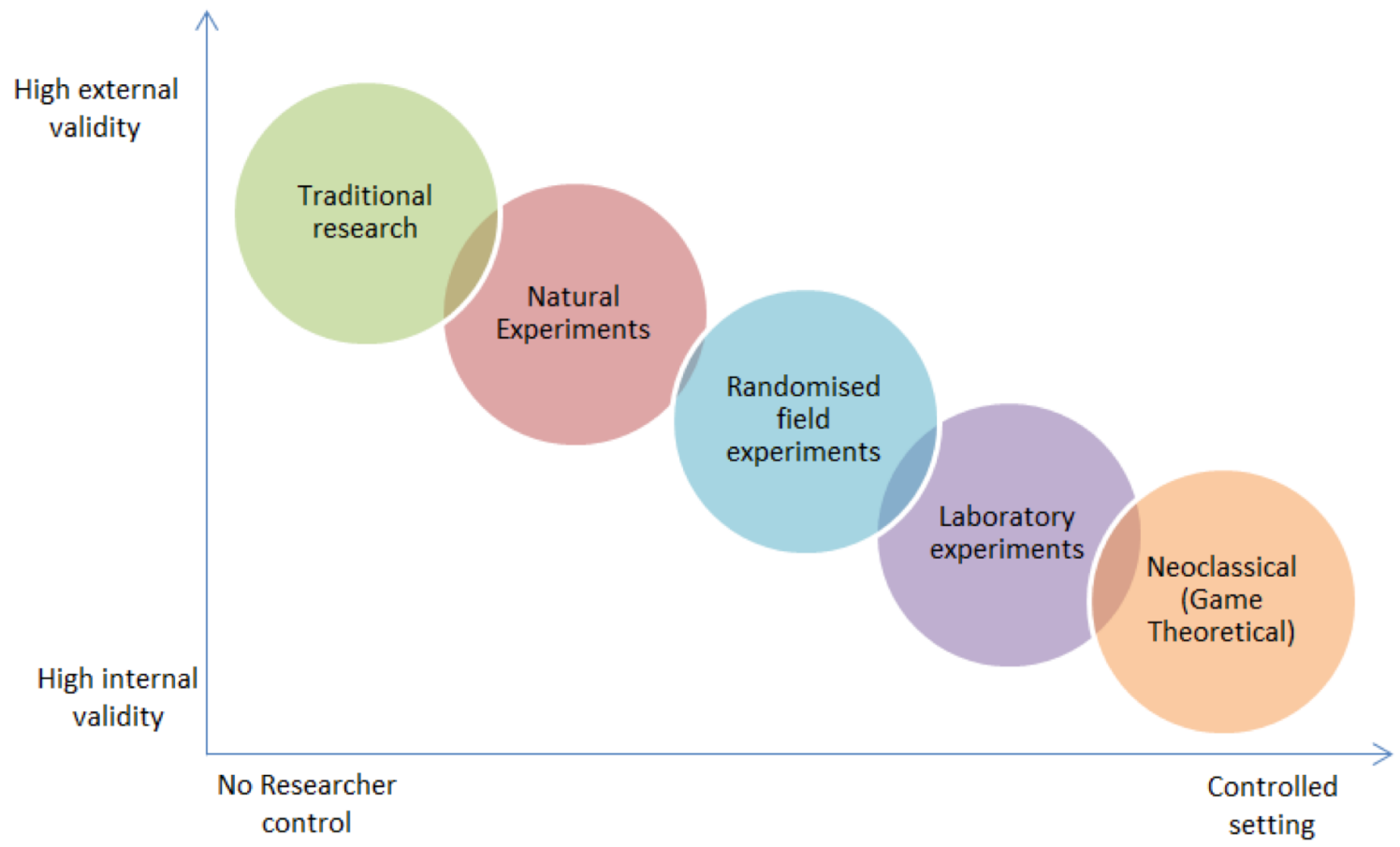

Fig. 1. Types of experiments, their features and delimitations (adapted from Sørensen, Mattsson and Sundbo (2010) and Weimann (2015))

2006), its value rests in reliance on naturalistic data (Ruiter and Albert 2017). Our premise for incorporating qualitative behavioural experiments in innovation research is based on the studies by Healey et al. (Healey, Howes, and Purver 2010; Healey, Purver, and Howes 2014) which refuted the highly cited laboratory findings of Branigan, Pickering and Cleland (2000), that people copy the verbal statements or words spoken by another during a dialogue more often than by chance. Qualitative behavioural experiments could enrich the quantitative experimental findings by providing an avenue to "stay conceptually closer to actual social behavior "in the wild"' (Ruiter and Albert 2017, p.97).

If how to increase individual and group (human) creativity, collaboration productivity and innovativeness in innovation projects is a concern, then perhaps behavioural experiments present as a solution. Behavioural experiments provide means to explain how certain conditions affect specific actions and outcomes. These tests can be more generalizable than conventional experiments if a well-considered design is employed. Methodological benefits arise as outcomes of various innovation aspects, from ideation to marketing of products, can be analyzed by manipulating underlying social and cognitive variables of interest. A key feature of behavioural experiments is that they can accommodate complex variables and contexts and thus allow for integrated abstraction of socio-cognitive capabilities to inform wider innovation procedures in practice. Innovation research and practice is naturally based on experimentation, be influenced by reflection of past experiences, judgements in current social context or desired future and, thus our perspective has its merits. 
In the next editorial, we will conclude the discussions on the science of managing for innovation with propositions for future research from a pragmatic stance. We will particularly highlight the role of behavioural experiments in advancing research at the intersection of human psychology and behaviour towards sustainable development. Meanwhile, we welcome your conceptual, theoretical, perspective and empirical contributions on topics that relate to innovation and its management.

Innovatively yours,

Anne-Laure Mention, João José Pinto Ferreira, Marko Torkkeli

The Editors

\section{References}

Adams, R., Jeanrenaud, S., Bessant, J., Denyer, D. and Overy, P., 2016. "Sustainability-oriented innovation: A systematic review." International Journal of Management Reviews, 18(2), pp.180205.

Ajzen, I., 2011. "The theory of planned behaviour: reactions and reflections." Pyschology $\&$ Health, 26(9), pp.1113-1127.

Antons, D. and Piller, F.T., 2015. "Opening the black box of "Not Invented Here": Attitudes, decision biases, and behavioral consequences." Academy of Management Perspectives, 29(2), pp.193-217.

Baskerville, R.L. and Wood-Harper, A.T., 1996. "A critical perspective on action research as a method for information systems research." Journal of Information Technology, 11(3, pp.235246.

Branigan, H. P., Pickering, M. J. and Cleland, A. A., 2000. "Syntactic co-ordination in dialogue." Cognition, 75(2): B13-B25.

Brüggemann, J. and Bizer, K., 2016. "Laboratory experiments in innovation research: a methodological overview and a review of the current literature." Journal of Innovation and Entrepreneurship, 5(1), pp.24.

Button, G. ed., 1991. "Ethnomethodology and the human sciences." Cambridge: Cambridge University Press.

Cannella Jr, A.A. and Paetzold, R.L., 1994. "Pfeffer's barriers to the advance of organizational science: A rejoinder." Academy of Management Review, 19(2), pp.331-341.

Charness, G., Gneezy, U. and Kuhn, M.A., 2012. "Experimental methods: Between-subject and within-subject design." Journal of Economic Behavior \& Organization, 81(1), pp.1-8.

Chetty, R., 2015. "Behavioral economics and public policy: A pragmatic perspective." American Economic Review, 105(5), pp.1-33.

Ferraro, F., Etzion, D. and Gehman, J., 2015. "Tackling grand challenges pragmatically: Robust action revisited." Organization Studies, 36(3), pp.363-390. 
Fischer, M.M., 2001. "Innovation, knowledge creation and systems of innovation." The annals of regional science, 35(2), pp.199-216.

Gross, M. and Krohn, W., 2005. "Society as experiment: sociological foundations for a selfexperimental society." History of the Human Sciences, 18(2), pp.63-86.

Healey, P. G., Howes, C. and Purver, M., 2010. "Structural divergence in dialogue." In Proceedings of the Conference on Architectures and Mechanisms for Language Processing, Los Angeles, CA. p. 103.

Healey, P. G., Purver, M. and Howes, C., 2014. "Divergence in dialogue." PloS one, 9(6).

Hinojosa, A.S., Gardner, W.L., Walker, H.J., Cogliser, C. and Gullifor, D., 2017. "A review of cognitive dissonance theory in management research: Opportunities for further development." Journal of Management, 43(1), pp.170-199.

Kautonen, T., Gelderen, M. and Fink, M., 2015." Robustness of the theory of planned behavior in predicting entrepreneurial intentions and actions." Entrepreneurship Theory and Practice, 39(3), pp.655-674.

Kitzinger, C., 2006. "After post-cognitivism." Discourse Studies, 8(1), pp.67-83.

Maddux, H.C. and Donnett, D., 2015. "John Dewey's Pragmatism: Implications for Reflection in Service-Learning." Michigan Journal of Community Service Learning, 21(2), pp.64-73.

Madrian, B.C., 2014. "Applying insights from behavioral economics to policy design." Annu. Rev. Econ., 6(1), pp.663-688.

Malachowski, A. ed., 2013. "The Cambridge Companion to Pragmatism." Cambridge: Cambridge University Press.

Newman, I. and Benz, C.R., 1998. "Qualitative-quantitative research methodology: Exploring the interactive continuum." Carbondale, Illinois: SIU Press.

O'Donohue, W., 2016. "Progress in innovation and knowledge management research: From incremental to transformative innovation." Journal of Business Research, 69(5), pp.1610-1614.

Ruiter, J.P. and Albert, S., 2017. "An appeal for a methodological fusion of conversation analysis and experimental psychology." Research on Language and Social Interaction, 50(1), pp.90107.

Shaughnessy, J. J., Zechmeister, E. B. and Zechmeister, J. S., 2015. "Research Methods in Psychology," New York, USA: McGraw-Hill.

Sniehotta, F.F., Presseau, J. and Araújo-Soares, V., 2014. "Time to retire the theory of planned behaviour." Health Psychology Review, 8(1): 1-7.

Sørensen, F., Mattsson, J. and Sundbo, J., 2010. "Experimental methods in innovation research." Research Policy, 39(3), pp.313-322.

Weimann, J 2015, "Die Rolle von Verhaltensökonomik und experimenteller Forschung in Wirtschaftswissenschaft und Politikberatung," Perspektiven der Wirtschaftspolitik, 16(3), pp.231-252.

Willer, D. and Harry, A., 2007. "Building experiments - testing social theory," California, USA: Stanford University Press. 
Appendix: A short-list of studies incorporating behavioural experiment methods 


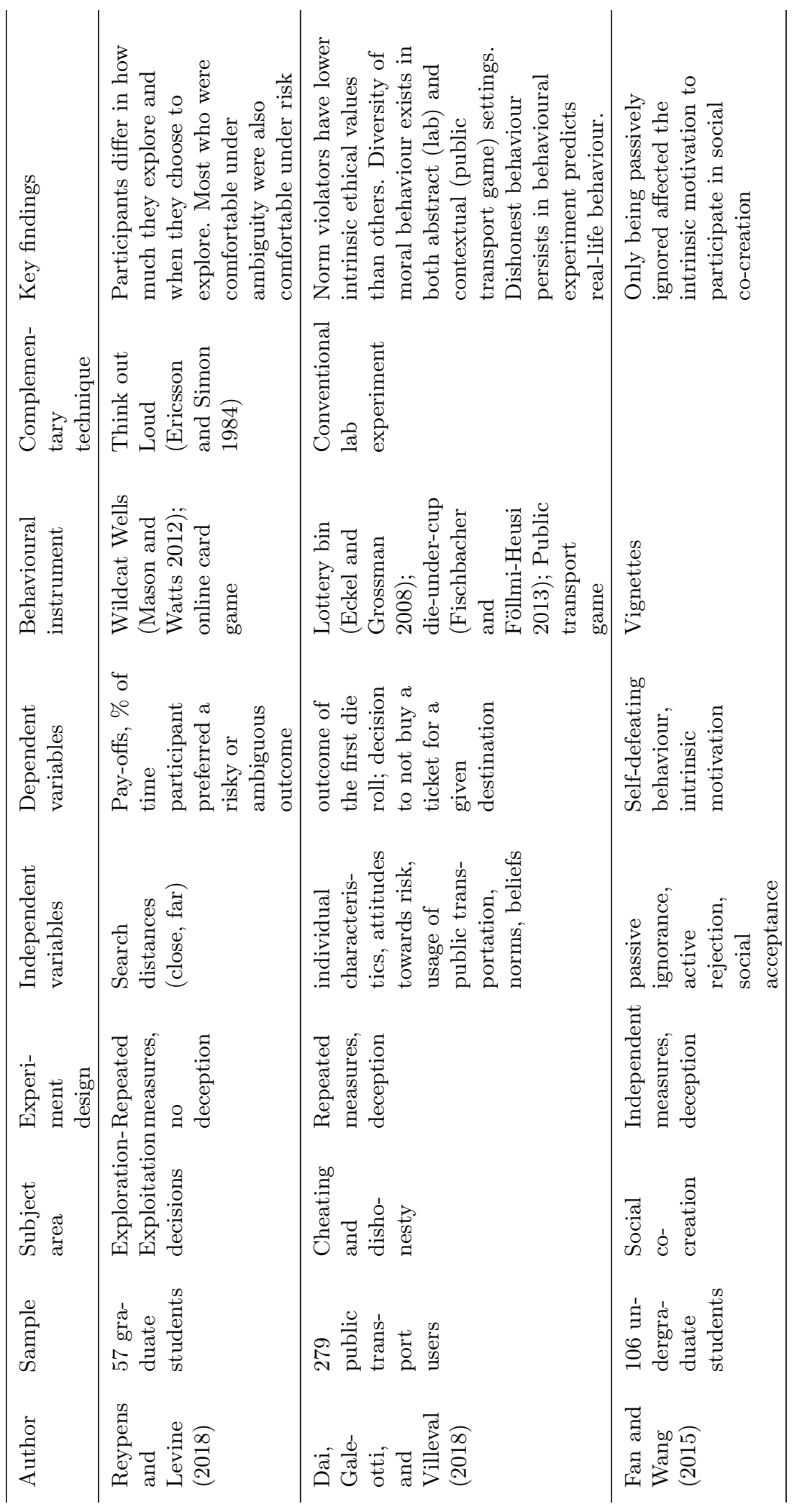




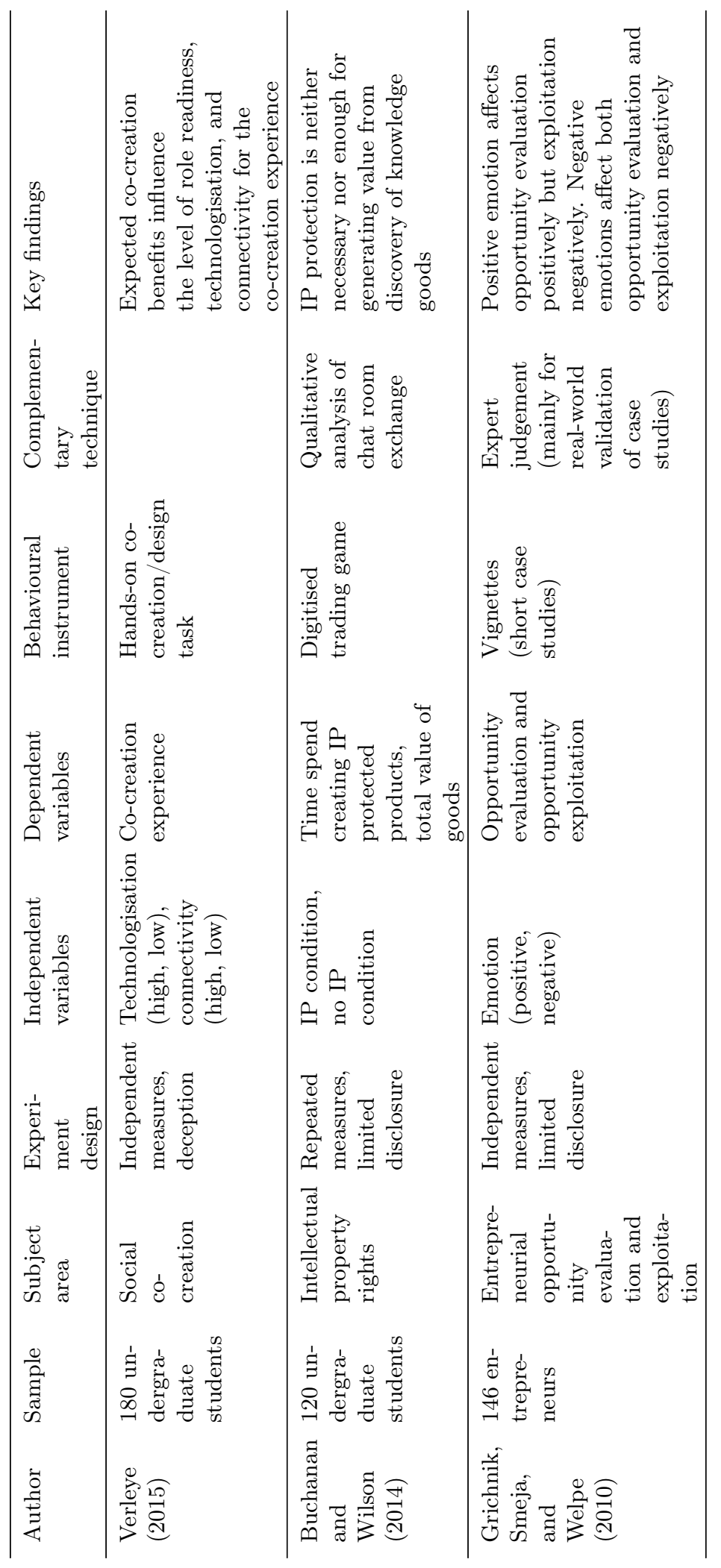

